\title{
Academic Excellence through Multi-Sensory Approach: A Model for Classroom Teaching
}

\author{
Gururaj Itagi $^{1}$ \& Laveena D’Mello ${ }^{2}$ \\ ${ }^{1}$ Research Scholar, Srinivas University, Mangalore, Karnataka, India \\ Email: gururajitgi@gmail.com \\ ${ }^{2}$ Dean, School of Social Sciences\& Humanities, Srinivas University, Mangalore, Karnataka, \\ India \\ Email: lavynoronha@gmail.com
}

Area/Section: Education.

Type of the Paper: Research Paper.

Type of Review: Peer Reviewed.

Indexed in: OpenAIRE.

DOI: http://doi.org/10.5281/zenodo.3544137.

Google Scholar Citation: IJMTS

How to Cite this Paper:

Itagi., Gururaj \& D’Mello, Laveena. (2019). Academic Excellence through Multi-Sensory Approach: A Model for Classroom Teaching. International Journal of Management, Technology, and Social Sciences (IJMTS), 4(2), 74-86.

DOI: http://doi.org/10.5281/zenodo.3544137.

International Journal of Management, Technology, and Social Sciences (IJMTS)

A Refereed International Journal of Srinivas University, India.

IFSIJ Journal Impact Factor for $2018=4.764$

(C) With Authors.

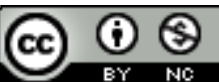

This work is licensed under a Creative Commons Attribution-Non Commercial 4.0 International License subject to proper citation to the publication source of the work.

Disclaimer: The scholarly papers as reviewed and published by the Srinivas Publications (S.P.), India are the views and opinions of their respective authors and are not the views or opinions of the SP. The SP disclaims of any harm or loss caused due to the published content to any party. 


\title{
Academic Excellence through Multi-Sensory Approach: A Model for Classroom Teaching
}

\author{
Gururaj Itagi ${ }^{1}$ \& Laveena D’Mello $^{2}$ \\ ${ }^{1}$ Research Scholar, Srinivas University, Mangalore, Karnataka, India \\ Email: gururajitgi@gmail.com \\ ${ }^{2}$ Dean, School of Social Sciences\& Humanities, Srinivas University, Mangalore, Karnataka, \\ India \\ Email: lavynoronha@gmail.com
}

\begin{abstract}
Human senses are natural contributions which transform the information to the brain for further processing to understand what is being presented to an individual through sight, hearing, touch, smell, taste. Senses will also determine the understanding of the different concept being presented and recall those contents or information for the right situation for the right action. To help the individual learner, teachers in various educational institutions should understand and apply the Multi-Sensory Approach in presenting their teaching contents in a classroom teaching to reach out the uniqueness of the individual learner's learning style and bring the best academic excellence. With the main aim of helping learners with their unique learning style, the "Itagi's Model of Multi-Sensory Approach” is been developed by Gururaj Itagi. Highlighting various methods, strategies and techniques in teaching process focussing on individual learning style to maximize student's academic excellence. This model is framed based on the different learning style of students. This framework considers integrated phases of teaching such as auditory, visual and kinaesthetic approach. The model focuses on Adolescence (aged 12-18 years) mainly on students with scholastic backwardness.
\end{abstract}

Keywords: Academic Excellence, Multi-Sensory Approach, Classroom Teaching, Students \& Teachers.

\section{INTRODUCTION :}

Classroom is a place in an educational institution where teachers, as well as students, are engaged in the teaching and learning process. Teachers and students will also have an academic interaction for the specified academic objectives. So, the classroom in the school must include the necessary materials which will support the teachers and students to have expertized teaching and effective learning. Many students in the school with scholastic backwardness are disengaged from inculcating knowledge and strengthening their long term memory. For the scholastic backwardness these students have less encouragement for learning. This is one of the important concepts of influence were children withdraw themselves from classroom learning, lack in their better academic excellence.To find effective solutions for different complications been noticed in the teaching-learning process, teachers in the schools must be trained and educatedto use different types of teaching methods and techniques which are included in amulti-sensory approach to reach the students learning styles and maximize their aptitude.

The Present Status of Teaching and Learning in Indian Schools: The new Education Policy2019 which is prepared by Dr. Kasthuri Rangan committee and asked for public opinion recognises, from information received by teachers, students, educational scientists, and educators of different sectors, that the present curriculum content is currently overloaded[1]. 
Many in school with scholastic backwardness are disengaged from inculcating knowledge and strengthening their long term memory. In addition to low academic achievement, these students can have low motivation for learning. Students are most of the time expected to respondfor the way in which the teacher teaches in the classroom rather than responding through their personal pathway of learning. Most of the time students are not given appropriate social support in classroom learning process, but they are always expected to give competition to their classmates, neighbours or their siblings rather than increasing self-trust and make themselves as competitor [2].

This is one of the important concepts of influence were children withdraw themselves from classroom learning, lack in their better academic outcome. Generally, we understand the way of learning as learning style but the scientific meaning of this term used is "sensory pathway" or a method through which an effective and experiential learning takes place. This sensory pathway is mainly categorized into three different modalities such as visual (sight) auditory (hearing) and kinaesthetic (movement). The learning style is nothing other than the way students respond to the classroom learning, involve and comprehend the content taught [3] [4].

School fear (School Phobia) among children is affecting the academic performance of the children and their day today's activities. In most of the schools the corporal punishment is considered as a traditional method of controlling the students and teachers often use it on students which makes students to develop a fear of attending school and classroom learning. This is also one of the major reasons for children's school dropout. It is highly recommended to expertise the teachers to have an insight into phobic disorders and their impacts on children. So that they can adopt an approach in teaching which encourages the students towards learning and makes them as active learners [5]. The children with several behavioural problems in the school are not given importance to understand the real cause behind their problems. There is a concept in the schools that negative approaches are the best methods to control the children; so frequently the same methods are used to approach the child which is, again and again, damaging the psycho-social wellbeing of the children in the school. Different programs must be planned to strengthen the children's capacity to cope with challenges and to make them emotionally strong, a flexible environment in the school must be created to make the child develop academically and socially [6].

\section{Need of Student Centred Classroom Teaching} for Academic Excellence: Different Committees set up by MHRD proposed "Learning Without Burden" and highlighted the sever need for reducing and revising our overcrowded curriculum content load in favour of a more engaging, holistic, experiential, and analysis-based form of learning. This gives us a deeper input of the need for changes in classroom teaching and the word experiential refers to the learning through being both physically and mentally present in the teaching and learning process. For creating a holistic learning environment in the classroom and engaging students in active learning the teachers must understand student's demands and different styles of learning [1]. When such an effort is made in the classroom teaching to give a multisensory experience of learning to the students and bring out the best academic excellence. Academic excellence refers to the increased level of learning interest, active participation in teaching and learning process, experiential learning based on individual learning style and Maximized performance in learning and examination. This will be achieved by the implementation of Multi-Sensory Approach model in classroom teaching [6].

\section{OBJECTIVES:}

The below objectives are setup with the aim of identifying strengths and weakness of present teaching methodology and explore the effective teaching approach which is mainly focused on the different learning styles of learning individuals in the classroom. The objectives of this study as below.

1. To Understand the different goals of MultiSensory Approach Model. 
2. To explore the experiential learning through Multi-Sensory Approach Model.

3.To develop the student-centred classroom teaching through Multi-Sensory Approach model.

4.To understand the different benefits from the use of Multi-Sensory Approach model.

\section{GOALS OF MULTI-SENSORY APPROACH:}

There are different materials available on building successful classroom teaching and this study specifically focused on the benefits of the multi-sensory approach on classroom teaching. This particular study also focussing on the classroom approach aiming to teach the individual's learning needs based on their learning style such as auditory, visual and kinaesthetic learning. The study also supports that the pupils can gain benefits through experience-based teaching in obtaining maximized knowledge and motivated participation of the pupils and they became less favourable to traditional teaching versus experiential learning [7]. The major goals of Multi-sensory approach are as follows.

Learners are the beneficiaries of the given information in the classroom, these may include different skills, knowledge or experience at a particular duration. But students differ in their academic strengths and also in their learning styles which makes them unique. This differences among students might be attributed to their senses and ability of perception in the brain. Senses and perception contribute to learn and retain the information received. Some individuals learn the information better through the hearing, some through the sight, and some individuals through their physical involvement in the learning process. But the combination of all the three pathways of learning is been proved to be more efficient as well as effective in the teaching-learning process for the better understanding of the information. Learning style is generally divided into three different types such as Visual Learning, Auditory Learning and Kinaesthetic Learning. Based on the individual's sensory abilities.

Visual Learners: Individual who learn better by using his or her visual organs is called as a visual learner. Visual learners use their eyes effectively in the learning process and enjoy learning. Most of the time these individuals like watching things, people around, objects and retain information as long term memory. Visual learners can easily remember information that they learnt through observing colours, shapes and pictures. By this way of learning an individual can have increased comprehension of the information been presented through visualization and easily recall that information in the right situations. Visualized teaching in the classroom was found to significantly increase student learning. The Multi-Sensory Approach is aiming to include teaching strategies which suites to the visual learners and prefers visualization of the subject in classroom teaching [8].

Auditory Learners: some individual prefers their auditory senses for better learning. This type of learners is active in using their years for the better hearing of the information been presented to them in the form of melodies sound. Individuals with auditory learning style will always have better comprehension if the information giving or classroom teaching will be done in the form of an oral way of presentation. The melodies vice of teacher, using audio aids in classroom teaching may enhance the learning interest and understanding level of auditory learners. The Multi-Sensory Approach also includes the effective teaching methods which focus on the learning demand of the auditory learners. The approach describes a possible way of effective teaching in the classroom considering auditory learners to maximize their academic performance as well as their learning interest [9].

Kinaesthetic Learners: some individuals enjoy learning and retain information through their physical and mental involvement in the learning process. These individuals always prepare their bodily involvement in learning through active participation in different learning activities. They always process information when there is an opportunity for their physical movement or participation in a learning situation. Activities, group discussion and physicalparticipationbased 
teaching are most effective for kinaesthetic learners. Encouraging student's bodily movement and physical involvement in classroom teaching and learning process will always benefit the kinaesthetic learners from these types of "hands-on" teaching approaches. These types of learners may not actively participate in the teaching approach based on the auditory and visual method of teaching. So, the aim of the multi-sensory approach is to fulfil the gap in encouraging the students with kinaesthetic learning style in teaching-learning process at the classroom and enhance their understanding ability to maximize their academic performance[10].

The different visual, auditory, and kinaesthetic learners learn better through when a specialized and expertized approach is done based on their learning style. Our minds have these different types of representations for gathering information. These different representations may more or less effective for preserving a variety of information. Somebody with visual representation and some with auditory. An Individual with kinaesthetic representation may not be good learners when the auditory and visual approach is done in classroom teaching. Children probably do differ in how good their visual, auditory and kinaesthetic memories are, but in most situations, it makes little difference in the classroom. So, considering learner's learning capacity the Multi-Sensory Approach brings a new strategic model which helps the teachers to reach every individual in the classroom with different learning style and maximize their active participation in teaching and learning process, increase their academic performance [10].

\section{EXPERIENTIAL LEARNING THROUGH MULTI-SENSORY APPROACH:}

The Indian education system is facing serious challenges in providing quality education and nurturing of students. These include the infrastructure of comparable quality, improving output, efficiency, and effectiveness of the teaching strategy. In recent years, there has been a considerable understanding of the decentralized leading team and influence of the community in the school's education system, the outcome is not as expected. This is happening due to the inadequate planning and lack of managerial and professional competencies at various levels in the education sector. Tensions experienced by the teacher in handing over greater classroom control to pupils is highly noticed. Child-centered ideas in the classroom have to be planned in teacher-training programs and school with the intention of creating more child-friendly, democratic learning environments and teaching based on student's learning demands focusing on their learning style may enhance better academic output [11].

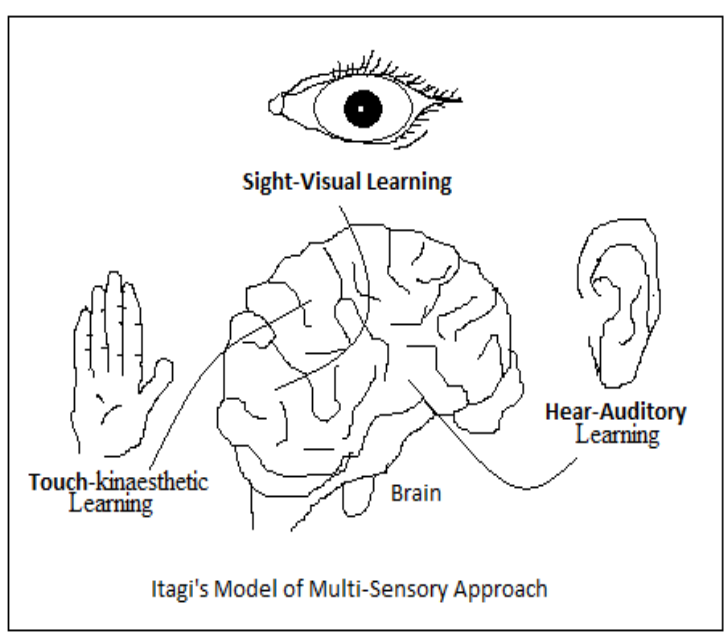

Fig.1: Human learn through sensory organs

Information obtained through senses such as hearing, seeing, touching, tasting, and smelling all contribute to the way in which people experience their external world. When an individual witness a situation he receives information through his multi-sensory organs. When an Individual see something happening, hear the sound produced and physically involve in the same situation will have a better understanding of what he saw, heard and involved. The message received on any one situation, concept, thing etc through multisensory organs will enhance the long term memory. For example, one student in the classroom for the first time is taught about litchi fruit through the explanation method, the student never seen, tasted, smelled and touched litchi fruit. After some days his father brought some 
litchi fruits and asked him which fruit is this? The son was not sure, because for the first time he could see, touch, smell and taste this type of fruits. The other student in the classroom was taught about the litchi fruit for the first time through the Multi-Sensory method approach. A teacher has given a fruit to the student to touch, see, smell and taste. After some days his father brought some litchi fruits and asked which fruit is this? The student was confident enough to identify the litchi fruit. To strengthen and enhance student's understanding capacity and reach learning sensitivity we developed Itagi's Model of Multi-Sensory Approach that aims to maximize the student's memorizing capacity for the different sensory modalities. It has a quality of personal involvement and being present in the learning event [12] [13].

Multi-Sensory Approach providing experiential classroom learning is participative, interactive, and motivating. It allows students to have contact with the classroom environment, and exposure to experience the teaching and learning process. It also involves the individual centred learning on the effective and behavioural dimensions as well as on the cognitive dimension. Learning objectives need to be specified before we plan for the specified teaching approach in the classroom. Students need to evaluate the experience in which they feel motivated, understood, memorized and actively participated in learning and teaching activities. Multi-Sensory Approach model outlines the manner in which learners gain knowledge and understanding through experiences [14].Students should have frequent and multiple opportunities to read, write, listen, see, speak and involve in the teaching and learning process. Lesson activities can be modified more appropriately to meet the student's learning needs and abilities. Modification techniques include a generalization of the subject to teach, adopting multiple methods of approach such as the use of body language, dictation, visualization of the subject, using audio-visual aids, practice-based teaching etc. A multi-sensory approach is not only offering participants to have structured experiences but also a reflection upon these experiences in order to learn from them, to link them to their own lives and to experiment with this new knowledge in the following activities and in their daily life which also contains long term memory [15].

Teachers play a major role in the effective class experience of students. It is the responsibility of the teacher to make his/her class interesting by adopting effective teaching strategies, preferring student's learning style, so that students are motivated to actively participate and have a better understanding of the teaching in the class. If the students are not encouraged to learn through their learning style by giving importance for their learning essentials and teacher use only chalk and talk method (Traditional method) of teaching students may adopt some destructive behaviour and indiscipline in their classroom involvement. Such students also develop a negative attitude towards the subject and teachers and they miss out on learning. They usually bunk or are irregular to the class. They don't even bother to be present for the class. Due to inappropriate teaching approach of the teachers in the classroom, many students just don't value their education. A fresh look at the approach to classroom teaching is required. The MultiSensory Approach in classroom teaching focuses on the learning demands of the students and encourages the students to have experiential learning in the classroom [16].

\section{DEVELOPING A STUDENT- CENTRED CLASSROOM TEACHING THROUGH MULTI-SENSORY APPROACH:}

Most of us have occupied knowledge and gone through different levels of learning without fully understanding the unique ability in learning or effectively using oursenses. Every individual made with a natural ability of senses those help the individual to receive, process and retain the information. But most individuals are not fully aware of their own sensory abilities of learning. This is also a reason why some of the individuals are not cooperative or active in the classroom learning process and by this, the traditional way of teaching strategies are becoming ineffective. An integrated approach in 
the classroom teaching will definitely optimize the teaching and learning process in the classroom which helps the individual learner with his unique style of learning and enhance his or her understanding ability [17].

Classroom teaching based on student's learning style thrives on several benefits. First, the teachers can have better understanding on the student's cognitive abilities in learning which will help them to alter their teaching style from traditional way of teaching in to effective method concentrated into student's specified learning style. Second, students are attracted towards teachers teaching and reduced distractions or classroom barriers where teachers can flexibly and effectively influence the students with their modified way of teaching. Third, even students will also can increased their comprehension in which they can maximize their academic performance. Fourth, increased awareness on cognitive skills will enhance student's abilities to take the best decision in learning process. Classroom teaching based on student's learning style will also build the better understanding as well as a good relationship between students and teachers. Making students to have improved academic performance in each subject explained in classroom teaching in-order to create more comprehensive, motivated, experiential, influencing and discussion based learning. Multi-Sensory Approach in classroom teaching is recommended, which even helps the teachers to get reduced burden of working with scholastic backward students. Teaching should be done in a more interactive method, students must be encouraged for discussion, and which should also include more creative and exploratory activities for better learning comprehension [18] [19].

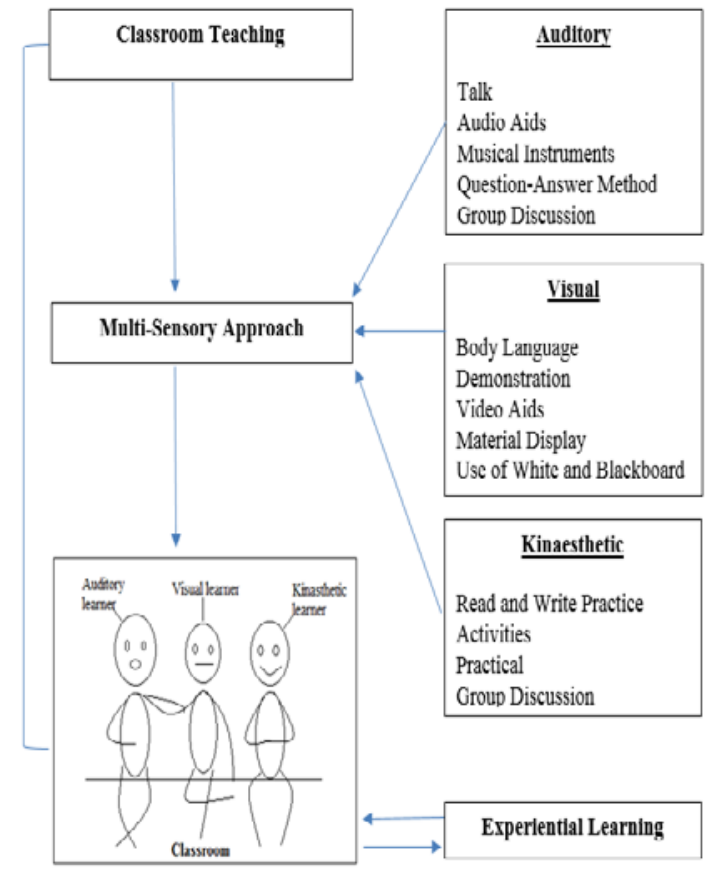

Fig.2: Multi-Sensory Approach Model

Approach for Auditory Learners: Auditory learner depends on remembering information taught through sounds. Who is doing the speaking is not a matter for the auditory learner, it may be a recording, and Teacher's talk or even himself reading. Chanting a word in a rhythmic way is even more effective method to help the auditory learners to recall the correct information and motivate them to have a better understanding of the material taught. Auditory learners naturally concentrate on different sounds, by that they get benefited more teachers teach in the classroom by using sound patterns rather than the written patterns. Because these types of learners depend more on their auditory memory. It is a responsibility of teachers that they adopt an effective teaching method as explained below [20].

(a) Talk: the teacher in the classroom teaching should be well trained in effective communication and be capable to pronounce the words fluently and melodiously. So that the students who are auditory learners enjoy their teaching and have a better understanding of the concept taught in the classroom. 
(b) Audio Aids: In the process of teaching teachers can also use different audio gadgets such as speakers, audio player, and mike etc. teachers can record teaching and help the students who would like to listen to it whenever they want. Teachers also can play melodious background music which when they have a session in the classroom.

(c) Musical Instruments: Using different musical instruments to play the music in the classroom will influence the auditory learners towards paying attention and active involvement in the teaching and learning process.

(d) Question and Answer Method: Students must be encouraged and given the opportunity to ask the questions and give answers. If the teachers make their session as most interactive one student will defiantly have to enjoy learning and improve their academic performance.

(e) Group Discussion: Even auditory learners enjoy having more discussion in the learning and teaching process. Teachers must encourage the students to have interaction between teachers and students and students and students. Teachers also can divide students into multiple groups and encourage them for group discussion.

Approach for Kinaesthetic Learners: The kinaesthetic learners will always focus more in activities based learning, they always would like to participate in many different learning activities for been conducted in the school. They are also interested in physical participation in any activity to understand and retain the information gathered as long term memory. This involvement will also help the students to focus on the learning process through active participation and understanding through experiences. So that teacher's creativity in converting their traditional way of classroom teaching in to more activity based teaching which will encourage the students and grab the student's attention toward better understanding the teaching and increases the active participation of the students towards learning and teaching process. The activity-based teaching planwill encourage student's physical involvement in the learning and teaching process which will help the kinaesthetic learners to comprehend the information in their style of learning. This activity based learning may include various projects, research activities, group discussions, brain storming activities, roll play, lab related experiments and field visits. Careful planning by the teacher in classroom teaching with kinaesthetic learners will enhance student's capacity in learning and maximize their academic performance because kinaesthetic learners acquire information by sharing and cooperating with teacher and peers [21][3].

(a) Read and Write Practice: Teachers can encourage students with a kinaesthetic learning style to have repetitive reading and writing practice. So that students will get engaged both physically and mentally in the teaching and learning process.

(b) Activities: Different activities planned by the teachers in classroom teaching also will encourage the students to get physically involved in the learning process. Roleplay, Drama, Indoor and Outdoor activities, research projects, experiments etc are the best methods to influence the students with kinaesthetic learning style towards better learning.

(c) Practical: Use of laboratories, indoor and outdoor experiments, demonstration related to the lesson will help the kinaesthetic learners to enjoy learning and have increased understanding.

(d) Group Discussion: Students with a kinaesthetic learning style must be encouraged for the group discussion so that they actively involved in clarifying doubts and sharing information.

Approach for Visual Learners: Visual learners enjoy receiving information through their eyes. Visualization of lessons in classroom teaching will enhance visual learner's active participation in the teaching and learning process. Displaying videos, writing on white or blackboard, effective use of the digital board, teacher's body language etc are the effective methods through which visual learners enjoy learning and increase their academic performance [22]. 
(a) Body Language: Body language is one of the effective methods for effective communication. Visual learners understand better when teachers use body language along with classroom teaching. Facial expressions, body movements and actions will effectively pass the messages to the learners. But most of the teachers in Indian schools even don't move from one place when they are in classroom teaching.

(b) Demonstration: Teachers can convert any lessons into the demonstration. Using a few students or he or she can put themselves to present the demonstration on any decided concept. More than orally explaining the lessons converting them in a visualized method of demonstration is better for visual learners to have an effective understanding and maximized academic performance.

(c) Video Aids: Different technologies such as Digital boards, TV, Video projectors etc can be used effectively in classroom teaching so that the visual learners can experience and have improved understanding of the lessons taught in the class. Teachers can plan their subject teaching as a visualized method of teaching using power point presentation, showing related videos, short films, animated videos which even influence more for the visual learners for better learning.

(d) Material Display: In the process of teaching, the teacher can display any materials or things related to the lesson. For example, a teacher would like to teach about triangles or any others shapes so she can use a triangle made in wood or any other materials to the students so that the visual learners have visualized learning about the triangle.

(e) Use of White and Black Board: Every classroom has a chalkboard that may be blackboard or whiteboard, these boards must be used effectively. Teachers must use the boards for writing the concept planned to teach. Drawing, writing title, an important point, mind map, calculation, tables, map or any other diagrams are the effective methods presenting on board to teach visual learners effectively.

\section{ACADEMIC EXCELLENCE THROUGH MULTI-SENSORY APPROACH:}

Poor teaching in the classroom hasa more direct impact on the reading performance of children [23]. Multi-Sensory Approach has the capacity to help the student with different learning style to have an efficient and effective understanding and realisation of the importance of teachinglearning objectives. It also helps the teachers to setup a better plan and arrange the teaching activities flexibly to make students with multidimensional learning needs to understand the concept taught. Organizing classroom teaching activities in an effective way by which students learn better through multi-sensory organs. However, every individual experience the outer world involves a unique multisensory approach. In the Multi-Sensory Approach model visual, auditory and kinaesthetic information are put together into different teaching-learning activities and many tasks that involve generalized explanation and physical as well as mental involvement of the learners during the classroom learning process. Therefore, the individual's brain has set up in such a way that the brain works to learn, pursue, and react with the help of multisensory environments[24]. Organized teaching process and learning activities been included in the classroom teaching will surely help the teachers to focus on the student's learning ability. It will also help students in acquiring maximum knowledge and a deeper comprehension of concept been taught in the classroom. Even the teacher also can encourage the students for their active involvement and cooperative response in the classroom [18].

In the multi-sensory process, students integrate sensory responses for three different methods such as vision, audition and touch that helps better for the maximized classroom learning. This will also help the students understand different modalities for comprehension as well as experience can be acquired on the subject taught in the classroom [12].The Multi-Sensory Approach Model makes its primary focus on engaging students in a process that best enhances their learning capacity. Learning will be conceived as a continuing reconstruction of 
learning experience [25]. We are learning information through multi-sensory modalities in the external world. By Multi-Sensory Approach in classroom learning process integrates all the sensory stimulation such as audio-visual and kinaesthetic based information been included in the classroom teaching. It will also integrate different tasks which are the best pathways for the different learning styles of the students in classroom learning. Even though students are preferred learners in a specific learning modality also can have better learning experience from amulti-dimensional teaching approach that mainly focuses on multi-sensory organs. The highly stimulated brain can have increased perception, maximized learning and deeper comprehension in classroom environments in which an integrated model of Multi-Sensory Approach is been carried out. However, MultiSensory-Approach strategies can even influence individual learners with their best and preferred learning style in a heterogeneous classroom [26].

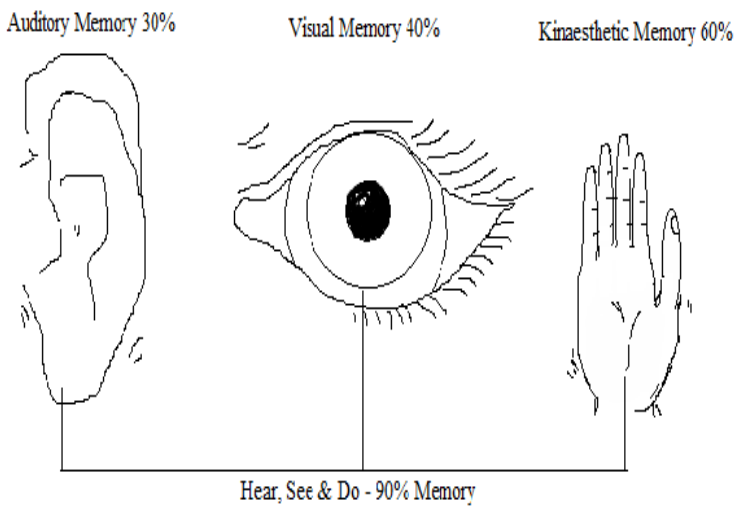

Fig.3 : Memory Benefits from the MultiSensory Approach [27].

Students with different learning style in the classroom have better learning experience when the information shared in classroom teaching is been presented with an integrated approach. The benefits of multi-Sensory Approach can be seen in students such as increased student's active participation in teaching and learning process. It also increases student's knowledge in required learning skills and different ways or modalities to acquire the knowledge been given in the classroom [10]. The utilization of the Senses of
Sight, Speech, Hearing and Touch of the individual in order to learn will enhance their learning ability and maximises there learning interest. This model is also helpful for children, as well as those with learning disabilities, children learn more effectively using their multi senses [1].When students were taught with Multi-Sensory Approach resources, (although initially through their most preferred learning modality), increased performance in academic as well as active participation in the learning process can be seen. This is one of the effective methods for influencing learners in classroom teaching in three different ways. The first way is helping the learners to get the information been presented in the external world through different senses. The next one will maximize the learner's perception capacity for a better understanding of the information taken to the brain. And the last way is helping learners to take the right decision and respond for the appropriate situation or task [28] [3]. There are no spirits than the motivation to influence an individual towards achieving their learning goals. The greatest achievers always lay down behind the inspiration of one or another person's, situations or by the stories of success. Motivation is an important aspect behind life leaving of each mankind. The presented model plays a major role in the creation of great hope and motivation among students in classroom learning [29][30].

\section{RECOMMENDATIONS:}

The following recommendations were suggested:

(a) To overcome the different teaching-learning challenges, teachers are recommended to get trained using different methods of teaching approaches, using teaching materials and active physical and mental involvement in the classroom teaching process.

(b) Teachers also recommended getting trained using Multi-Sensory Approach in classroom teaching to maximize the learning experience of the learners with different learning style in the heterogeneous class.

(c) Educational institutions are recommended to provide fully equipped classrooms and welltrained teachers to convert traditional classroom 
teaching into expertized classroom teaching. (d) Teachers are recommended to encourage the students for visual, auditory and activity-based learning with their preferred learning style.

(e) Educational institutions must be taken initiation for providing the necessary support for the teachers to work for the better academic output using necessary classroom resources to enhance Multi-Sensory Approach in classroom teaching.

\section{CONCLUSION:}

Sight, hearing, touch, smell, taste are the different senses for an individual to receive information from the external world. Understanding the uniqueness of an individual learner's learning style, teachers use MultiSensory Approach which integrates different techniques in order to help the learners for the better comprehension of the content taught in the classroom [31].This Multi-Sensory Approach model must be adopted as a value addition to the formal education system to build effective teaching and experiential learning in the classroom setting for maximized academic excellence of the students which will also result for achieving hundred percent literacy with wellinculcated individuals.

\section{REFERENCES:}

[1] Kasturirangan, K. (2019). Draft of National Education Policy-2019. Human Resource Development Government of India. https://mhrd.gov.in/sites/upload files/mhrd/fi les/Draft_NEP_2019_EN_Revised.pdf.

[2] Guthrie, J. T. \& Davis, M. H. (2003). Motivating struggling readers in middle school through an engagement model of classroom practice. Reading \&Writing Quarterly, 19(1), 59-85. DOI: https://doi.org/10.1080/10573560308203.

[3] Adams-Gordon, \&Beverly, L. (2010). The benefits of multisensory spelling instruction.Castlemoyle

Books.http://www.spellingpower.com/articles /BenefitsMultisensorySpellingInstruction.pdf

[4] Daneman, M. \& Carpenter, P. A. (1980).
Individual differences in working memory and reading. Journal of verbal learning and verbal behaviour, 19(4), 450-466. DOI: https://doi.org/10.1016/S00225371(80)90312-6.

[5] Gouda, Gururaj Ganapati \&D’Mello, Laveena (2019). Phobia: Impact on Academic Outcomes of Students Aged Between 6 Years to 18 Years - A Case Study. International Journal of Case Studies in Business, IT, and Education (IJCSBE), 3(1), 20-27. DOI: http://doi.org/10.5281/zenodo.2586233.

[6] Gouda, Gururaj Ganapati \&D’Mello, Laveena (2019). A Study on the TeacherStudent Relationship and its Impact on the Behaviour of High School Students. International Journal of Case Studies in Business, IT, and Education (IJCSBE), 3(1), 28-34.

DOI: http://doi.org/10.5281/zenodo.2589822.

[7] Kaldi, S., Filippatou, D. \&Govaris, C. (2011). Project-based learning in primary schools: effects on pupil's learning and attitudes. Education, 39(1), 35-47. DOI: https://doi.org/10.1080/03004270903179538.

[8] Dwyer Jr, F. M. (1968). An experiment in visual learning at the eleventh-grade level. The Journal of Experimental Education, 37(2), 1-6. DOI: https://doi.org/10.1080/00220973.1968.1101 1104.

[9] FilizKayalar \&FethiKayalar (2017). The effects of Auditory Learning Strategy on Learning Skills of Language Learners (Students' Views). IOSR Journal of Humanities and Social Science (IOSR-JHSS), 22(10), 04-10.

[10] Willingham, D. T. (2005). Do visual, auditory, and kinesthetic learners need visual, auditory, and kinesthetic instruction. American Educator, 29(2), 31-35.

[11] Gururaj Ganapati Gouda \&LaveenaD'Mello (2019). Excellence through Value Education - A Case Study of Sharada Vidyanikethana Public 
School.International Journal of Case Studies in Business, IT, and Education.3(1).DOI: http://doi.org/10.5281/zenodo.2558062.

[12] Sonneveld, Marieke H., Ludden, Geke D.S. \&Schifferstein, Hendrik N.J. (2019). MultiSensory Design in Education. Zenodo. DOI: http://doi.org/10.5281/zenodo.2596133.

[13] Gais, S., Lucas, B. \& Born, J. (2006). Sleep after learning aids memory recall. Learning \& Memory, 13(3), 259-262. http://learnmem.cshlp.org/content/13/3/259.f ull.html.

[14] Fatemeh Mollaei, M. A. (2012). Experiential Education Contributing to Language Learning. International Journal of Humanities and Social Science, 2(21). http://www.ijhssnet.com/journals/Vol_2_No_ 21_November_2012/31.pdf.

[15] Masilamani, C. \&Sundarsingh (2019). The Act of Learning from Experience: A Theoretical Study of Experiential Learning in English Language Classroom. Research Journal of English Language and Literature, 7(1).http://www.rjelal.com/7.1.19/436441\%20MASILAMANI\%20C.pdf.

[16] Ritu Chandra (2015). Classroom Management for Effective Teaching. International Journal of Education and Psychological Research, 4(4). https://www.researchgate.net/publication/313 889949 Classroom Management for Effect ive_Teaching.

[17] Hochreiter, S. \&Schmidhuber, J. (1997). Long short-term memory. Neural computation, 9(8), 1735-1780. DOI: https://doi.org/10.1162/neco.1997.9.8.1735.

[18] Pradeep, M.D.and Kalicharan, M. (2016). Life Centric Skill Enrichment Framework-An Effective Pedagogy for Empowerment. International Journal of Computational Research and Development (IJCRD),1(1). 40 46.https://ssrn.com/abstract $=2852737$

[19] Ogata, H., Saito, N. A., Paredes J. R. G., San Martin, G. A., \& Yano, Y. (2008). Supporting Classroom Activities with the
BSUL System. Educational Technology \& Society, 11 (1), 1-16. https://www.jets.net/ets/journals/11_1/1.pdf.

[20]Thelen, A., Matusz, P. J.\& Murray, M. M. (2014). Multisensory context portends object memory. Current Biology, 24(16), R734R735.

[21] Diaz, D. P. \&Cartnal, R. B. (1999). Students' learning styles in two classes: Online distance learning and equivalent oncampus. College teaching, 47(4), 130-135. https://pdfs.semanticscholar.org/e311/564a31 698c10636b8d5d6182e7b392d87575.pdf.

[22] Akkoyunlu, B. \&Soylu, M. Y. (2008). A Study of Student's Perceptions in a Blended Learning Environment Based on Different Learning Styles. Educational Technology \& Society,11 (1), 183-193. https://pdfs.semanticscholar.org/708e/a13e96 5a1efeaac8b462e564afaa010d500b.pdf.

[23] Joshi, R. M., Dahlgren, M. \& BoulwareGooden, R. (2002). Teaching reading in an inner city school through a multisensory teaching approach. Annals of Dyslexia, 52(1), 229-242.

https://link.springer.com/article/10.1007/s118 81-002-0014-9.

[24] Shams, L. \& Seitz, A. R. (2008). Benefits of multisensory learning. Trends in cognitive sciences, 12(11), 411-417. DOI: https://doi.org/10.1016/j.tics.2008.07.006.

[25] Alice Y. Kolb \& David A. Kolb (2011). Experiential Learning Theory: A Dynamic, Holistic Approach to Management Learning, Education and Development. The SAGE Handbook of Management Learning, Education and Development. DOI: http://dx.doi.org/10.4135/9780857021038.n3.

[26] Kim, R. S., Seitz, A. R. \& Shams, L. (2008). Benefits of stimulus congruency for multisensory facilitation of visual learning. PLoS One, 3(1), e1532.

[27] Aja, S. N., Eze, P. I., Igba, D. I., Igba, E. C., Chika C., Nwafor, S.C., Nnamani (2017). Using Multi-Sensory Instruction in Managing Classroom for Effective Teaching and 
Learning. International Journal of Applied Engineering Research, 12(24). https://www.ripublication.com/ijaer17/ijaerv 12n24 163.pdf.

[28] Jay Caulfield and Treesa, Woods (2013). Experiential learning: Exploring its long-term impact on socially responsible behaviour. Journal of the Scholarship of Teaching and Learning,13(2), 3-48. https://files.eric.ed.gov/fulltext/EJ1011680.p df.

[29] Gouda, Gururaj Ganapati \&D’Mello, Laveena (2019). Introducing “Cap Concept” in a Class Room Learning for the Students to Achieve Success. International Journal of Management, Technology, and Social Sciences (IJMTS),4(1), 38-45. DOI: https://doi.org/10.5281/.

[30] Drago-Severson, E., Helsing, D., Kegan, R., Broderick, M., Popp, N. \&Portnow, K. (2001). Three developmentally different types of learners. Focus on basics, 5(B), 7-9. http://ncsall.net/index.php@id=256.html.

[31] ShreepathyRanga Bhatta. B. \& Varun Kumar, S. G. (2017). A Study of Student Perception on Printed Study Material Distribution Model at Srinivas Institute of Management Studies. International Journal of Management, Technology, and Social Sciences (IJMTS),2(1), 66-74. DOI: http://dx.doi.org/10.5281/zenodo.821579.

$* * * * * *$ 